\title{
Avaliação do potencial tóxico dos resíduos sólidos urbanos da cidade de Campina Grande - PB
}

\author{
Evaluation of the toxic potential of \\ municipal solid waste city of \\ Campina Grande - PB
}

Alessandra dos Santos Silva ${ }^{1}$, Libânia da Silva Ribeiro ${ }^{2}$ Willian de Paiva ${ }^{3}$, Márcio Camargo de Melo ${ }^{4}$ Veruschka Escarião Dessoles Monteiro ${ }^{5}$

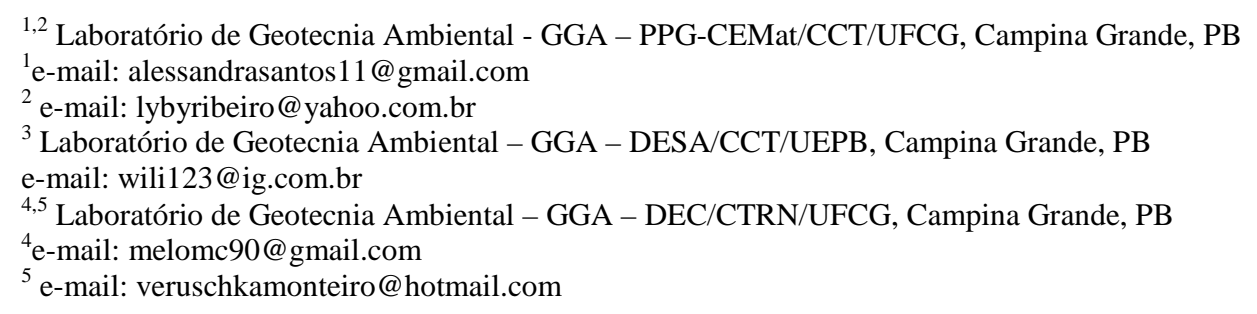

\section{RESUMO}

A grande heterogeneidade dos Resíduos Sólidos Urbanos (RSU) faz com que estes apresentem uma composição bastante variável, podendo muitas vezes, serem comparados aos resíduos industriais por possuírem substâncias a bases de metais pesados e outros componentes tóxicos que apresentam riscos a saúde e ao meio ambiente. Assim, a busca por alternativas tecnológicas para manejo adequado dos resíduos e entendimento do seu comportamento após destinação final, tem feito com que cada vez mais estudos sejam desenvolvidos para esse fim. Exemplo disso são os estudos realizados em células experimentais, feitos com o intuito de simular o comportamento de uma célula de aterro sanitário, entendendo todas as reações que ocorrem em seu interior sob condições controladas. O objetivo desse trabalho é avaliar o potencial tóxico dos RSU da cidade de Campina Grande - PB, presentes em uma célula experimental. O experimento consistiu em uma célula experimental dotada de toda instrumentação presente em uma célula de um aterro real. O monitoramento da célula foi feito durante um período de dois anos, sendo realizada a caracterização inicial dos resíduos no dia do seu preenchimento, posteriormente amostras mensais de resíduos foram coletadas. Os resultados obtidos mostraram que os RSU foram classificados como resíduos perigosos, por conterem em sua composição elevados teores de elementos traços como: Alumínio, Manganês e Níquel. Por fim, concluiu-se que a presença desses elementos juntamente com o nitrogênio amoniacal presente nos RSU não interferiu no processo de biodegradação, no entanto contribuiu para o efeito fitotóxico dos resíduos sólidos.

Palavras-chave: Fitotoxicidade, Célula experimental, Metais, Nitrogênio Amoniacal

\begin{abstract}
The great heterogeneity of Municipal Solid Waste (MSW) makes it presents a very variable composition and can often be compared to industrial waste substances by having the heavy metal bases and other toxic components that present risks to health and the environment. Thus, the search for alternative technologies for proper waste management and understanding of their behavior after disposal, has made more and more studies are developed for this purpose. Examples are studies in experimental cells, made in order to simulate the behavior of a landfill cell, understanding all the reactions that occur inside under controlled conditions. The aim of this study is to evaluate the toxic potential of MSW in the city of Campina Grande - PB, present in an experimental cell. The experiment consisted on the construction of an experimental cell that simulates a fullscale landfill. The monitoring of the cell was made during a period of 2 years, and held the initial characterization of the waste on the day of its completion later monthly samples of waste were collected. The results showed that the MSW were classified as hazardous waste because they contain in their composition high
\end{abstract}


levels of elements such as aluminum, manganese and nickel. Finally, it was concluded that the presence of these elements along with Ammoniacal Nitrogen present in the MSW did not interfere with the biodegradation process, however contributed to the phytotoxic effect of the solid waste.

Key Words: Phytotoxicity, Experimental cell, Metals, Ammoniacal Nitrogen.

\section{INTRODUÇÃO}

Por apresentar uma composição bastante variável, os Resíduos Sólidos Urbanos (RSU) podem muitas vezes ser comparados aos resíduos industriais por possuírem substâncias a base de metais pesados como pilhas, baterias, enlatados, tintas, eletroeletrônicos, entre outros, os quais são tóxicos e apresentam riscos à saúde e ao meio ambiente, quando dispostos de forma incorreta. No entanto, além dos metais pesados, os subprodutos gerados pela própria decomposição dos resíduos sólidos também podem causar toxicidade ao meio, a exemplo da amônia que em função dos elevados teores e das características do ambiente em que esta inserida pode torna-se tóxica.

A Associação Brasileira de Normas Técnicas (ABNT), por meio da sua NBR 10.004/04 [4], estabelece alguns critérios para classificação dos resíduos sólidos quanto ao potencial tóxico à saúde e ao meio ambiente que estes podem causar. No entanto, quando se tem dúvidas quanto a essa classificação, o enquadramento dos resíduos sólidos pode ser feito por meio de análises físico-químicas sobre o extrato solubilizado e/ou lixiviado obtido a partir da amostra bruta do resíduo, por meio de testes de lixiviação realizados de acordo com a NBR 10.005/04[5] e de solubilização NBR 10.006/04[6].

A avaliação da toxicidade das substâncias presentes nos resíduos sólidos pode ser medida por meio de ensaios de fitotoxicidade. Esses ensaios indicam as reações adversas das plantas quando em contato com substâncias tóxicas presentes no meio. Por isso, os testes de fitotoxicidade têm sido bastante utilizados para avaliar os danos causados pelas combinações tóxicas presentes nos RSU, após sua disposição final.

Dentre as alternativas de disposição final dos RSU, os aterros sanitários se constituem como uma das tecnologias mais eficazes, desde que operado de maneira adequada conforme requisitos da legislação. Uma vez depositados nestes ambientes, os resíduos sólidos se degradam naturalmente por via biológica até a mineralização total da matéria biodegradável, em condições fundamentalmente anaeróbias (CAMPOS e CAZARINI [9]). Contudo, o estudo do comportamento de aterros sanitários em grandes escalas ainda apresenta alguns empecilhos, principalmente devido à escassez desse tipo de aterro em nosso país.

Assim, entender os mecanismos de biodegradação e de lixiviação que ocorrem nos aterros sanitários torna-se menos complexo se estudos em células experimentais forem realizados. Essas células permitem compreender o comportamento de aterros de RSU e representam uma técnica bastante interessante para obter parâmetros de projetos, dimensionamento e construção de aterros, além do mais podem fornecer contribuições através de monitoramento dos processos biodegradativos (MONTEIRO et al. [22]). O objetivo desse trabalho é avaliar o potencial tóxico dos resíduos sólidos urbanos da cidade de Campina Grande - PB, presentes em uma célula experimental.

\section{MATERIAIS E MÉTODOS}

\subsection{Célula Experimental}

O desenvolvimento desta pesquisa consistiu na construção, preenchimento e monitoramento de uma célula experimental localizada na Universidade Federal de Campina Grande (UFCG). A célula possui 3,0 m de altura, 2,0 m de diâmetro interno e um volume total de $9,0 \mathrm{~m}$, sendo dotada de três orifícios para coleta dos resíduos sólidos, em níveis de profundidade denominados superior, intermediário e inferior, a partir dos quais foram retiradas amostras para monitoramento.

O experimento possui sistemas de drenagens de líquidos e gases, instrumentos de medição do nível de líquidos por meio de um piezômetro, medidores de recalque e de temperatura (termopares) ao longo de toda profundidade, além de sistemas de impermeabilização de base e cobertura de solo, com camadas de altura de $0,30 \mathrm{~m}$ e $0,20 \mathrm{~m}$, respectivamente e solo com permeabilidade de $2,40 \times 10^{-6} \mathrm{~cm} \cdot \mathrm{s}^{-1}$. A Figura 1 apresenta o desenho esquemático da célula experimental construída nesta pesquisa.

A célula experimental foi preenchida com RSU da cidade de Campina Grande - PB. Para isso, foi feita uma parceria com a Prefeitura Municipal de Campina Grande (PMCG) e escolhida em conjunto com o Departamento de Limpeza Urbana (DLU) uma rota de coleta de resíduos sólidos que abrangesse três bairros 
de diferentes classes sociais da cidade. Após coleta nos bairros, os resíduos sólidos foram encaminhados à UFCG, a fim de serem descarregados para posterior preenchimento da célula experimental.

O preenchimento foi feito com o auxílio de uma máquina retroescavadeira que levava os RSU, previamente pesados, até o interior da célula experimental, a fim de serem descarregados. Ao serem colocados na célula, os resíduos eram distribuídos em camadas e compactados com o auxílio de um soquete manual até atingir uma cota pré-estabelecida de $2,70 \mathrm{~m}$. O grau de compactação obtido foi de $0,7 \mathrm{t} . \mathrm{m}^{-3}$.

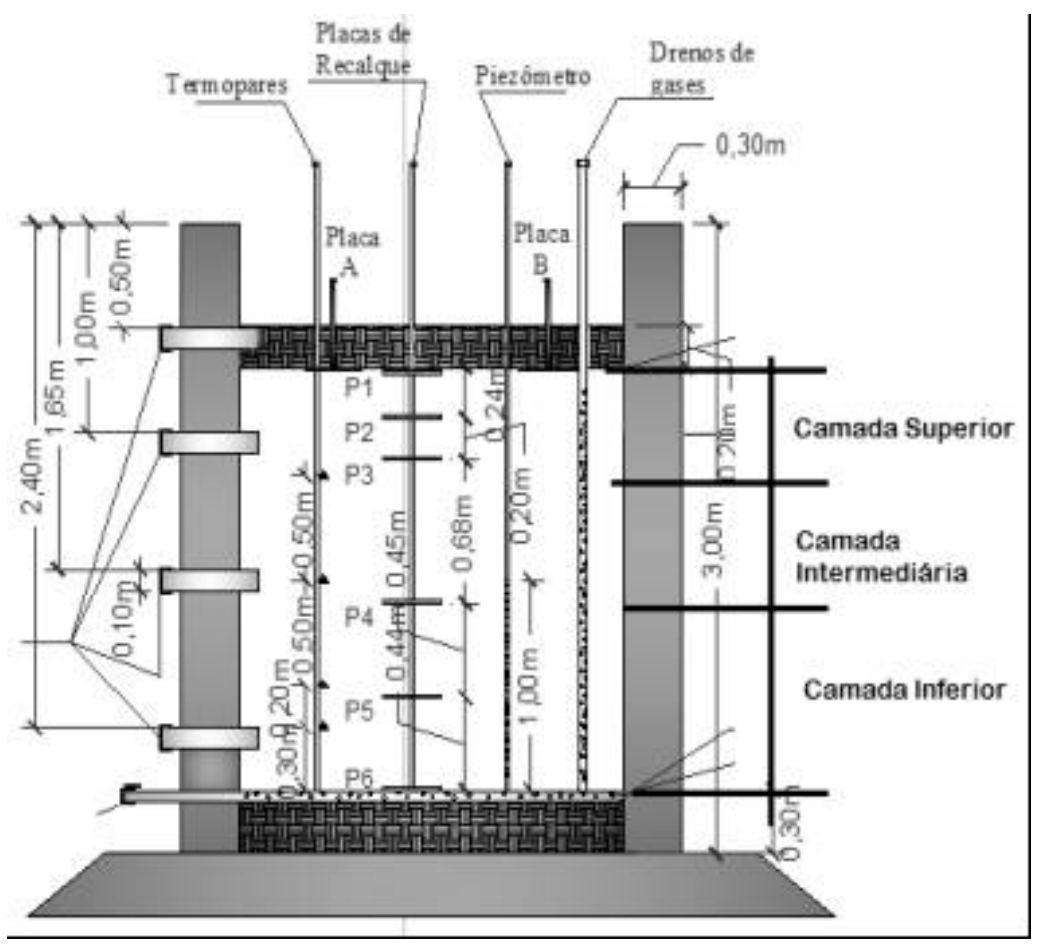

Figura 1: Desenho esquemático da Célula experimental de RSU.

Antes do preenchimento dos resíduos na célula experimental, foram feitos ensaios in-situ com a preparação do solo, para utilizá-lo como camada de base e cobertura impermeabilizante. Estas camadas, foram usadas com o intuito de evitar a contaminação por meio da lixiviação, bem como impedir o espalhamento dos resíduos e garantir as condições anaeróbias no interior da célula.

Para realização do monitoramento, inicialmente foi feita a caracterização inicial dos resíduos e mensalmente amostras de aproximadamente $900 \mathrm{~g}$ eram coletadas de cada altura da célula experimental, com ajuda de um amostrador manual, e encaminhadas ao laboratório, com o intuito de avaliar o comportamento dos resíduos sólidos aterrados ao longo do tempo e da profundidade. No laboratório, os resíduos coletados eram picotados, com auxilio de tesoura, em tamanho de aproximadamente $30 \mathrm{~mm}$ a $50 \mathrm{~mm}$ e imersos em água destilada por um período de 30 minutos, a fim de se obter um extrato líquido para análise das variáveis estudadas. O Quadro 1 apresenta as variáveis analisadas nesta pesquisa e as metodologias utilizadas.

Quadro 1: Variáveis estudadas e metodologias utilizadas nesta pesquisa

\begin{tabular}{|l|l|}
\hline VARIÁVEIS & MÉTODOS \\
\hline Nitrogênio Amoniacal, pH e Metais & APHA [3] \\
Testes de Lixiviação & NBR 10.005/04 [5] \\
Fitotoxicidade & TÍQUIA e HODGKISS [29] \\
\hline
\end{tabular}




\subsection{Ensaios de Fitotoxicidade}

Os ensaios de fitotoxicidade foram realizados segundo Tíquia e Hodgkiss [29], adaptado por Melo [19]. O procedimento para as análises consistiu em cultivar sementes de tomate (Lycopersicon lycopersicum) e repolho (Brassica oleraceae) em amostras de resíduos sólidos coletados na célula experimental.

As sementes utilizadas, nestes ensaios, passaram inicialmente por um processo de lavagem e desinfecção. Em seguida, foram colocadas em placas de Petri contendo papeis de filtro, a fim de receberem a amostra de RSU para posterior incubação em estufa BOD, por um período de 5 dias. As análises foram realizadas em triplicatas. Após o período de 5 dias, as sementes foram analisadas e observados os seus índices de germinação e crescimento, comparando-os com uma amostra em branco (água destilada), através das Equações (1) e (2):

Germinação Relativa da Semente (GRS):

$$
\mathrm{GRS}(\%)=\frac{\text { número de sementes germinadas }}{\text { número de sementes germinadas no controle }} * 100 E q .(1)
$$

\section{Crescimento Relativo da Raiz (CRR):}

$$
\mathrm{CRR}(\%)=\frac{\text { média do compriment o da raiz }}{\text { média do compriment o da raiz do controle } \sqrt{\text { cresciment o da raiz do controle }}} * 100 E q .(2)
$$

\section{RESULTADOS E DISCUSSÃO}

\section{$3.1 \mathrm{pH}$}

A Figura 2 apresenta a evolução do pH para os RSU depositados na célula experimental em estudo. Analisando a Figura, observa-se que o $\mathrm{pH}$ inicial dos resíduos sólidos é igual a 5,5. Estudos realizados por Tchobanoglous, et al. [28], Cintra [11] e Alcântara [2], indicam que o valor inicial de pH comumente encontrado em resíduos sólidos com a maior parte composta de materiais orgânicos é 6,0. No entanto, o tempo decorrido entre a geração dos resíduos e a sua chegada ao local de descarregamento, bem como a presença de bactérias fermentadoras de ácidos pode ter ocasionado uma diminuição no pH.

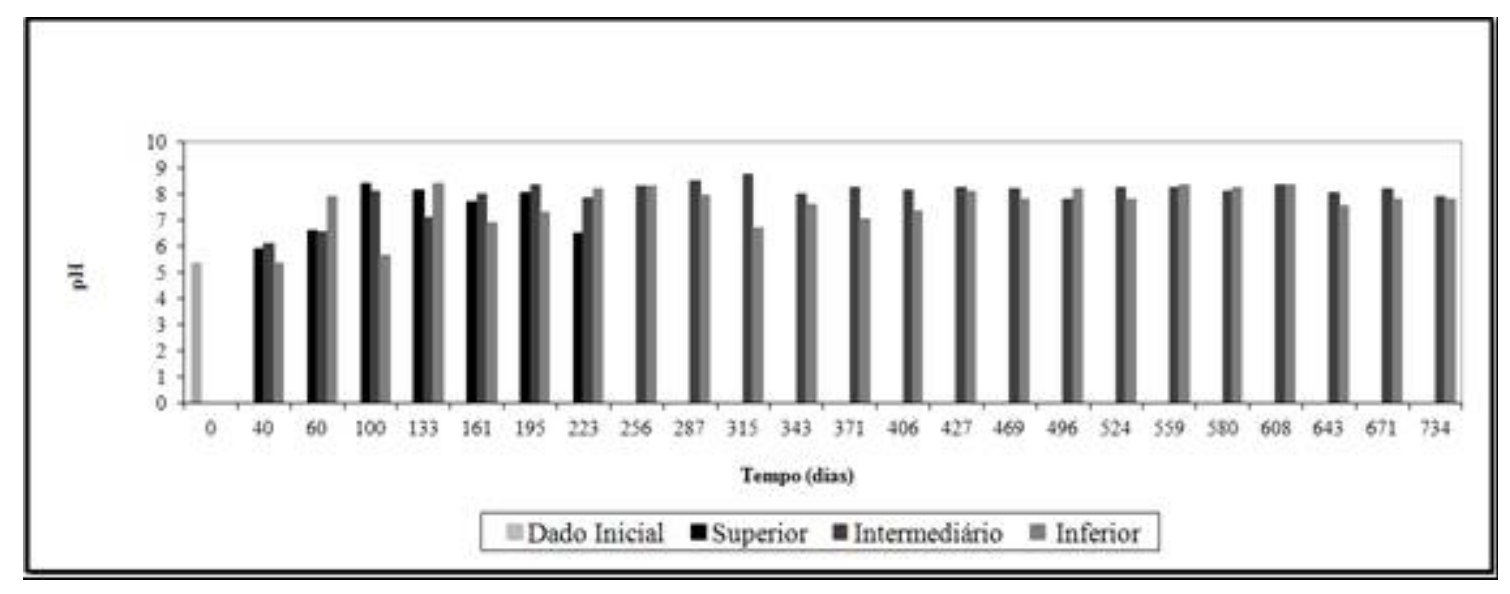


Figura 2: Evolução do pH ao longo do tempo e da profundidade na célula experimental.

Já nos primeiros 40 dias de monitoramento da célula experimental, o pH apresentou um leve aumento em todas as profundidades. Passados os 100 dias, observa-se que o valores do pH tendem a aumentar com valores próximos a neutralidade, indicando que possivelmente a célula experimental pode estar passando da fase de hidrólise para as fases posteriores de degradação da matéria orgânica, sendo que as fases de acidogênese e acetogênese não são claramente perceptíveis.

A evolução do pH concorre para o estabelecimento das fases posteriores de degradação, porém não se pode defini-las com exatidão, uma vez que pode ocorrer o estabelecimento de mais de uma fase ao mesmo tempo. A fase metanogênica ocorre em valores de $\mathrm{pH}$ variando entre 6,8 e 8,0 (TCHOBANOGLOUS et al. [28]). Nessa fase existe um grande numero de bactérias metanogênicas, que transformam os ácidos e hidrogênios presentes no meio em metano, reduzindo assim o número de ácidos e consequentemente aumentando o $\mathrm{pH}$.

\subsection{Nitrogênio Amoniacal}

A amônia ocorre em duas formas, que juntas são denominadas nitrogênio amoniacal total. Quimicamente essas duas formas são representadas pelo íon amônio $\left(\mathrm{NH}_{4}{ }^{+}\right)$, que não é tóxico, e pela amônia livre $\left(\mathrm{NH}_{3}\right)$ que é tóxica. A Figura 3 apresenta o comportamento do nitrogênio amoniacal para as amostras de resíduos sólidos coletados na célula experimental.

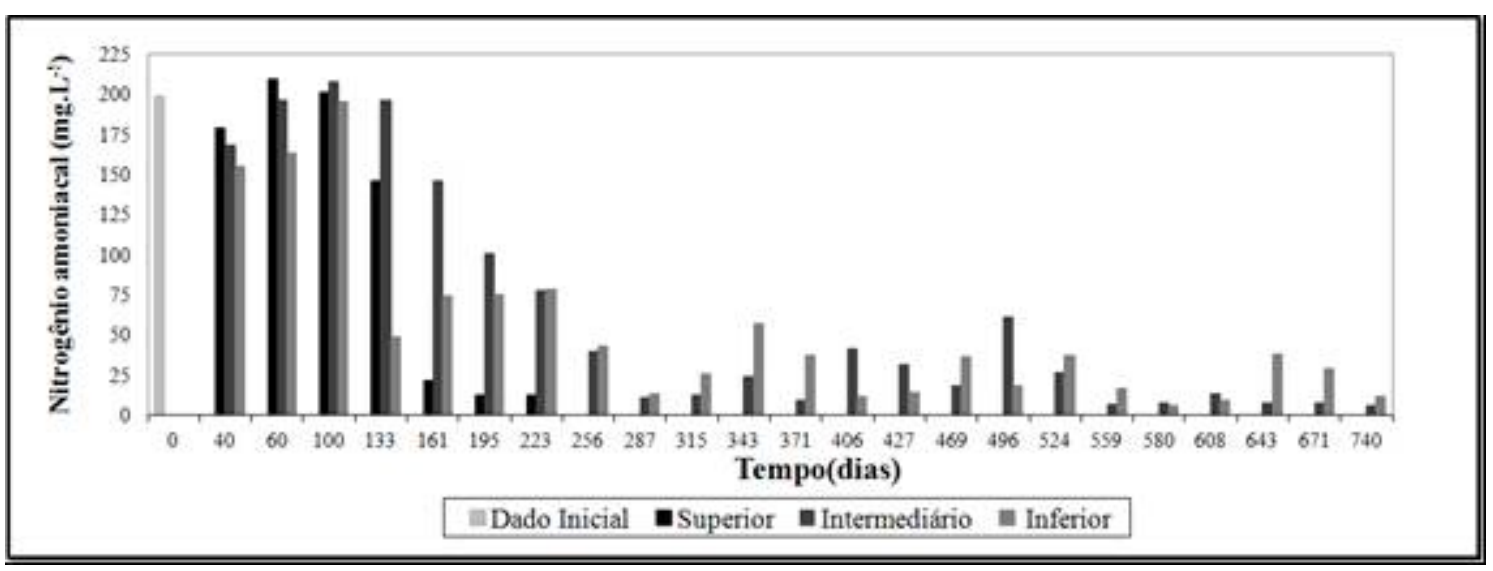

Figura 3: Concentração de nitrogênio amoniacal ao longo do tempo e da profundidade.

Analisando a Figura 3, pode-se observar que até os 100 dias de monitoramento a concentração média de nitrogênio amoniacal encontrada na célula experimental foi de $200 \mathrm{mg} . \mathrm{L}^{-1}$ e, após esse período ocorreu uma diminuição ao longo do tempo. De maneira geral, essa concentração elevada no início do monitoramento da célula experimental pode esta associada à degradação biológica de aminoácidos e outros compostos orgânicos nitrogenados, presentes no meio durante a fase acetogênica (EDUARDO, [12]).

No geral, percebe-se que as concentrações do nitrogênio amoniacal sofreram redução considerável, a partir os 133 dias de monitoramento, fato que pode este associado à evolução das fases de degradação, na qual os resíduos sólidos passam da acetogênese (fase característica de aumento do nitrogênio amoniacal) para metanogênese, que segundo Alcântara [2], é característica de baixas concentrações de nitrogênio amoniacal, devido o processo da bioestabilização da matéria orgânica.

Esta redução pode ainda, ter sido consequência da dessorção da amônia livre $\left(\mathrm{NH}_{3}{ }^{-}\right)$para a fase gasosa, uma vez que o pH do meio encontra-se acima de 7,5 favorecendo com isso, a presença desta forma sobre o íon amônio $\left(\mathrm{NH}_{4}^{+}\right)$, e/ou pela utilização desta amônia como fonte de nitrogênio pelos micro-organismos (RIBEIRO, [25]). Além disso, a presença de oxigênio no interior da célula experimental também pode ter contribuído para o desenvolvimento do processo de nitrificação e consequentemente, para redução dos teores de nitrogênio amoniacal. Embora, o ambiente da célula experimental tenha sido desenvolvido para apresentar características anaeróbias, durante o processo de monitoramento percebeu-se que alguns fenômenos contribuíram para entrada de ar na célula experimental, a exemplo das aberturas existentes nas laterais da célula expe- 
rimental, para coleta das amostras de resíduos, das fissuras existentes na camada de cobertura, além da entrada de água de chuva que traz consigo oxigênio dissolvido em sua composição. Estudos desenvolvidos por Calli et al. [8] mostram que o nitrogênio amoniacal é considerado tóxico em concentrações superiores a 600 mg. $\mathrm{L}^{-1}$. Como a concentração máxima encontrada na célula experimental é inferior àquela considerada tóxica, pode-se concluir que não houve influência direta do potencial tóxico do nitrogênio amoniacal no processo de biodegradação dentro da célula experimental. Silva [27] realizou estudos, referentes ao desenvolvimento de microrganismos, nesta célula experimental durante o mesmo período de monitoramento e observou que os microrganismos se desenvolveram de maneira satisfatória. Com isso, pode-se dizer a toxicidade do nitrogênio amoniacal no interior da célula experimental não exerceu influência sobre a atividade dos microrganismos e, consequentemente no processo de biodegradação.

\subsection{Elementos Traços}

A Tabela 1 apresenta o comportamento das análises de Alumínio, Manganês, Cobre, Níquel e Chumbo realizadas com RSU presentes na célula experimental e os Limites Máximos Permissíveis (LMP) estabelecidos pela NBR 10.004/04 [4] para os testes de lixiviação. As concentrações iniciais de Alumínio e Manganês foram de aproximadamente $30 \mathrm{mg} \cdot \mathrm{kg}^{-1}$, existindo uma tendência a variação desses elementos ao longo do tempo. Os elementos Cobre e Níquel apresentaram comportamento idêntico com uma concentração inicial de 2,2 mg.kg ${ }^{-1}$, havendo uma redução em sua concentração ao longo de tempo, ao passo que os valores encontrados foram inferiores a 2,0 mg. $\mathrm{kg}^{-1}$, fato que impossibilitou sua identificação pelo equipamento de leitura, visto que este só realiza medições em concentrações superiores a esta.

As análises de Alumínio, Manganês e Chumbo apresentaram concentrações elevadas, comparadas aos demais elementos, com variações em seus teores ao longo de todos os pontos de coleta de resíduos sólidos da célula experimental. Esses valores bastante diferenciados podem estar associados a grande heterogeneidade dos resíduos sólidos e a impossibilidade de homogeneização das amostras durante a coleta, sendo a amostra representativa aquela coletada pelo amostrador.

Para o Cobre, o Níquel e o Chumbo não foram detectadas concentrações desses elementos nos meses subsequentes, mesmo para o Chumbo, em que suas concentrações foram elevadas nos dois meses de monitoramento. Reduções nas concentrações desses elementos já eram esperadas, devido entre outros fatores, às fases do processo de degradação dos resíduos sólidos. Durante a fase ácida, caracterizada por baixos valores de $\mathrm{pH}$, em virtude da elevada produção de ácidos orgânicos, ocorre uma maior solubilização de metais. No entanto, com a evolução do processo de degradação e o estabelecimento das fases seguintes, nas quais se verifica a elevação do pH, ocorre, uma diminuição na solubilização dos metais, fato que justifica as baixas concentrações detectadas nas fases posteriores a de degradação ácida.

Tabela 1: Concentrações dos elementos trações e LMP pela NBR 10.004/04 para lixiviação

\begin{tabular}{c|c|c|c|c|c}
\hline & $\begin{array}{c}\text { Inicio monitoramento } \\
\left(\mathbf{m g . k g}^{-\mathbf{1}}\right)\end{array}$ & \multicolumn{3}{|c|}{ Após 40 dias de monitoramento } & LMP - Lixiviação \\
& Inicial & Superior & Intermediária & Inferior & \\
\hline & 30,4 & - & 48 & 25 & 4,0 \\
\hline Alumg.kínio & 30,0 & 8,8 & 10,0 & 7,4 & 2,0 \\
\hline Manganês & 2,2 & NI & NI & NI & 40 \\
\hline Cobre & 2,2 & NI & NI & NI & 0,4 \\
\hline Níquel & 6,0 & 3,6 & 8,2 & 6,2 & 20,0 \\
\hline Chumbo & & & &
\end{tabular}

NI = Não Identificável (Valores inferiores a 2,0 mg. $\mathrm{kg}^{-1}$ )

A NBR 10.004/04 [4] estabelece concentrações máximas permitidas, a fim de que os resíduos sólidos possam ser enquadrados em diferentes classes. Segundo esta norma, os Limites Máximos Permissíveis (LMP) de Alumínio para lixiviação é de $4,0 \mathrm{mg} \cdot \mathrm{kg}^{-1}$, valor bastante inferior ao encontrado na célula experimental. Os teores de Manganês, assim como os de Alumínio encontram-se acima dos valores máximos permissíveis. Na verdade, a NBR 10.004/04 [4] não apresenta valores máximos permissíveis para o Manganês. Seu enquadramento se dá por meio dos LMP estabelecidos pela Portaria 2.914/11 [7] do 
Ministério da Saúde. Para essa portaria, os limites estabelecidos para lixiviação desse elemento é de 2,0 mg.kg-1.

Para os elementos Cobre e Níquel os LMP encontrados em análises de lixiviação são respectivamente $40 \mathrm{mg} \cdot \mathrm{kg}^{-1}$ e $0,4 \mathrm{mg} \cdot \mathrm{kg}^{-1}$. Percebe-se, para esses elementos que os teores de Alumínio, Manganês e Níquel encontram-se acima do estabelecido pela norma, fato que permite o enquadramento dos RSU na classe I resíduos perigosos. Embora os RSU sejam normalmente considerados como resíduos não perigosos, a introdução de materiais de diversas origens em sua composição, aliada a ausência de programas de segregação na fonte tem alterado suas características, fazendo com que resíduos considerados isentos de contaminação apresentem características tóxicas. Isto porque quando não dispostos separadamente, os resíduos que não apresentam toxicidade entram em contato com as demais frações de resíduos ocasionando a sua contaminação.

$\mathrm{O}$ pH inicial dos resíduos, igual a 5,5, pode ter contribuído para que concentração do Alumínio, Manganês e Níquel fosse superior ao estabelecido pela NBR 10.004/04 [4]. Isso porque, muitos compostos de Níquel são relativamente solúveis com valores de $\mathrm{pH}$ abaixo de 6,5. Já o Alumínio e o Manganês tem sua solubilidade elevada com a diminuição do pH. Importante ressaltar, que as determinações dos elementos traços foram realizadas a partir do extrato lixiviado dos resíduos sólidos conforme NBR 10.005/05. Estudos desenvolvidos por Mesquita Filho e Souza [20], demonstram que esse elemento é especialmente tóxico em pH abaixo de 5,0, mas pode causar problemas mesmo quando o pH é 5,5.

Valores elevados de Alumínio e Manganês fazem com que os resíduos sólidos apresentem potencial perigoso de elevada toxicidade, comprometendo o meio ambiente no qual estes elementos estão inserido, uma vez que, mesmo anos depois ao seu descarte, os resíduos sólidos continuam se degradando e contaminando as fontes externas. A fração solúvel dos resíduos contaminados em água resulta da partição do metal entre as fases sólida e líquida do solo, e sua importância resulta dela representar a quantidade prontamente biodisponível no ambiente, bem como de ser passível de movimentação em profundidade no perfil do solo KABATA-PENDIAS \& PENDIAS [16], sendo arrastada através da lixiviação contaminando solos e lençol freático.

Os estudos realizados por Silva [27], nesta mesma célula experimental, mostram que, embora a presença de compostos tóxicos fosse elevada na célula experimental, não houve interferência desses compostos na atividade dos microrganismos, os quais são responsáveis pelo processo de biodegradação dos resíduos após aterramento. No entanto, apresentou-se tóxico para a saúde e o meio ambiente como pode ser observado nos ensaios de fitotoxicidade.

\subsection{Fitotoxicidade}

As Figuras 4 e 5 apresentam, respectivamente, os resultados dos ensaios de fitotoxicidade pela análise da Germinação Relativa das Sementes (GRS) e do Crescimento Relativo das Sementes (CRR), feitos com as sementes de tomate e repolho, nos diferentes níveis de profundidade da célula experimental ao longo do tempo. 

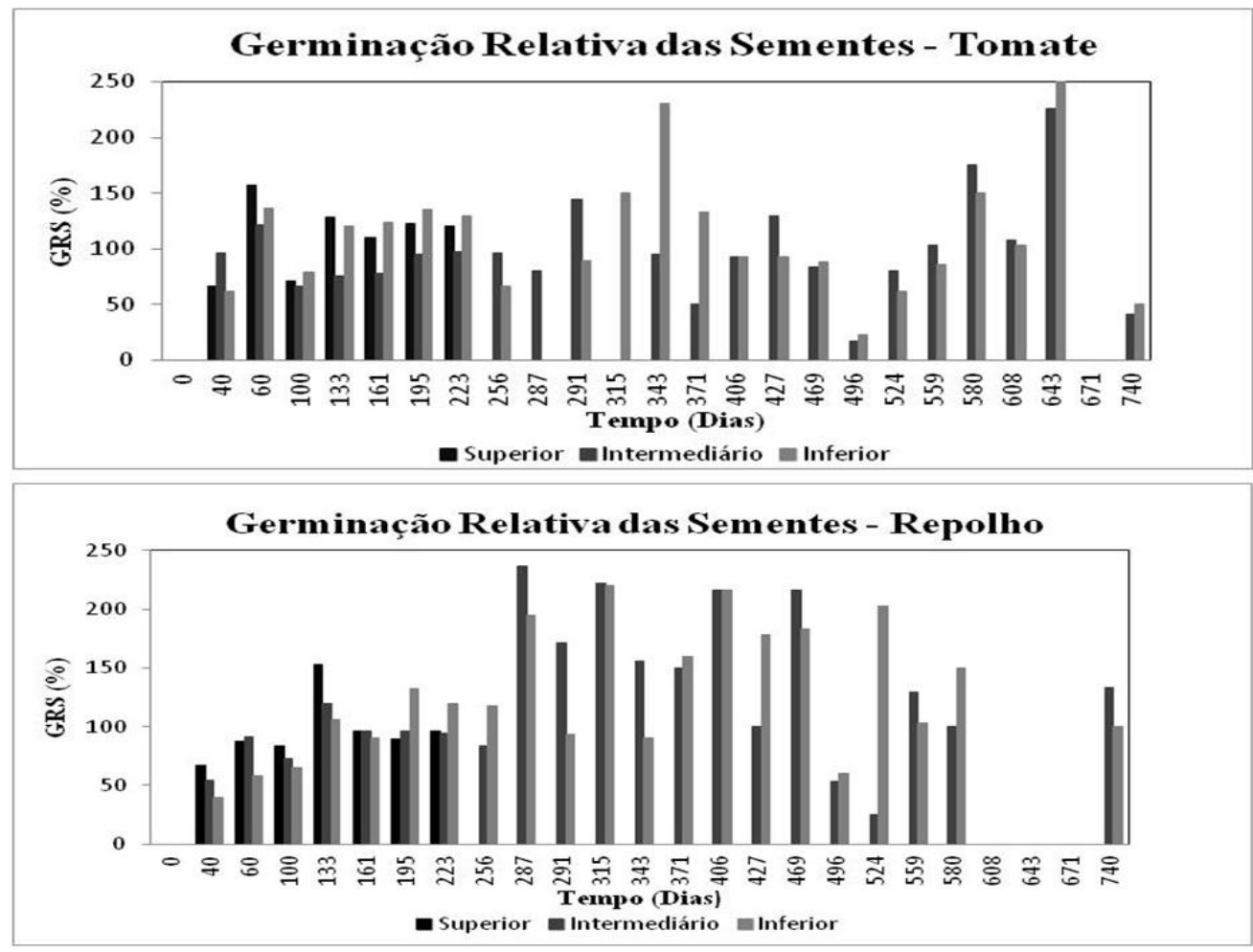

Figura 4: Germinação Relativa das Sementes (\%) para as sementes de tomate e repolho.

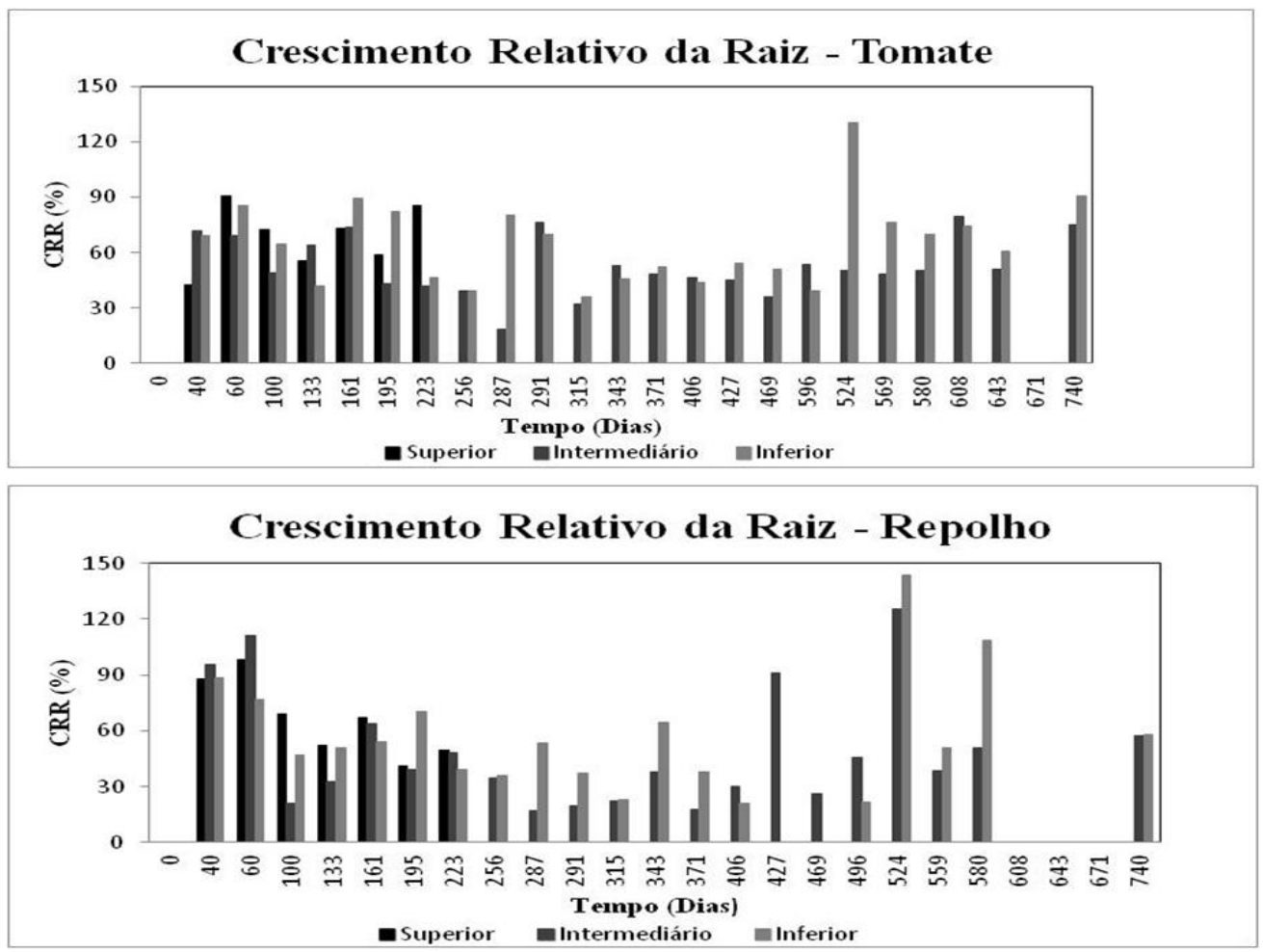

Figura 5: Crescimento Relativo das Raízes (\%) para as sementes de tomate e repolho.

Analisando as Figuras 4 e 5 relacionadas à GRS e ao CRR para as sementes de tomate e repolho, pode-se observar que, de maneira geral, os índices de GRS são maiores que os de CRR, isso ocorre porque o processo de germinação é menos sensível aos fitotóxicos presentes no meio. Por apresentarem reservas pró- 
prias de alimentos em sua constituição, as sementes tendem a utilizar essas reservas para nutrir-se, e só na ausência destas é que buscam nutrientes de fontes externas. Além disso, o processo de germinação é dependente de água, sendo a água o fator que mais influencia o processo de germinação. Com a absorção de água ocorre a reidratação dos tecidos e, consequentemente, a intensificação da respiração e de todas as outras atividades metabólicas que resultam no fornecimento de energia e nutrientes necessários para a retomada do crescimento por parte do eixo embrionário. Resultados semelhantes foram encontrados em trabalhos desenvolvidos por Melo [19] e Garcez [13].

Avaliando o CRR (Figura 5) pode-se observar que, em geral, as sementes de tomate apresentaram comportamento menos variável, ao longo do tempo e também maiores índices de crescimento em relação as sementes de repolho. Isso acontece, pois segundo Chang et al. [10] as sementes de repolho são mais sensíveis do que as de tomate por serem sementes muito pequenas, portanto, possuem pequenas quantidades de reservas de alimentos. Sendo assim, necessitam rapidamente de fontes externas de nutrientes.

Analisando a Figura 5, inicialmente pode-se observar um maior crescimento nos índices de CRR, nos primeiros meses de monitoramento. Esses índices maiores, em ambas as sementes, podem estar relacionados à maior quantidade de matéria orgânica no meio, que ainda apresenta-se em fase de intensa degradação, fato que diminui o efeito dos compostos tóxicos presentes na célula experimental. Com o passar do tempo, essa matéria orgânica, pelo fato de ser degradada pelos microrganismos, faz com que aumente a quantidade de materiais recalcitrantes, que podem afetar as condições do meio por serem de difícil degradação, gerando subprodutos com potenciais tóxicos e assim diminuindo os índices de crescimento das sementes. Por serem mais sensíveis, as sementes de repolho apresentam variações em seus índices de crescimento, diferentemente das sementes de tomates que, ao longo do tempo, mantém seus índices constantes, com esporádicos picos que podem estar associados à grande heterogeneidade dos resíduos sólidos.

Observa-se nas Figuras 4 e 5 que no monitoramento dos dias 608, 643 e 671 não houve germinação nem crescimento para as sementes de repolho e no dia 671 esse fato não ocorreu para as sementes de tomate. A ausência de crescimento e germinação dessas sementes pode estar associada à elevada carga tóxica presente na célula experimental. Essa toxicidade pode estar associada à própria coleta dos resíduos que não permite a sua homogeneização, podendo trazer consigo materiais pontuais de elevada toxicidade ou ainda a presença de nitrogênio amoniacal que nessa fase de monitoramento apresenta-se na sua forma tóxica, devido ao elevado $\mathrm{pH}$.

$\mathrm{O}$ pH é um fator que pode causar fitotoxicidade nos resíduos sólidos. Como se pode observar nas Figuras 4 e 5, respectivamente, não houve crescimento nem germinação dos resíduos sólidos na fase inicial. Nessa fase, os resíduos sólidos da cidade de Campina Grande - PB apresentam um processo inicial de decomposição com pH 5,5. Segundo Kiehl [17], o processo inicial de decomposição dos resíduos, apresenta-se como a fase fitotóxica, uma vez que, no início da decomposição biológica da matéria orgânica, geralmente se desenvolvem traços de diversos ácidos minerais e, em maior quantidade, os orgânicos, principalmente o ácido acético e toxinas danosas às plantas, que acabam fornecendo propriedades de fitotoxicidade ao material.

A presença de ácidos na fase inicial de degradação promove uma acidificação no meio, devido à fermentação inicial dos RSU, fato confirmado de estudos de Jahnel, et al. [14]. Porém, essa fase ocorre rapidamente, visto que as bactérias produtoras de ácidos têm um crescimento ótimo apenas na faixa de pH entre os 5,0 e os 6,0, fazendo assim, com que a fase fitotóxica seja também bastante rápida.

Relacionando-se os teores dos elementos traços com os testes de fitotoxicidade observa-se que, alguns elementos como o Alumínio, Manganês, Níquel, Cobre e Chumbo podem estar contribuindo para a inibição do crescimento e germinação das sementes.

A presença de Alumínio no meio pode causar efeito fitotóxico sobre o crescimento das plantas, uma vez que o Alumínio promove a acidez do meio. Relacionado ainda, os dados de Alumínio com os testes de fitotoxidade observa-se que após os 40 dias de enchimento da célula experimental o seu $\mathrm{pH}$ tende a crescer, embora apresente-se ainda na fase ácida, diminuindo o efeito fitotóxico do Alumínio sobre as sementes. Uma possibilidade para redução do efeito do Alumínio sobre as sementes é a elevada presença de Cálcio no meio que tende a neutralizar seu efeito, fato que foi constatado por Silva [27] em estudos realizados nesta mesma célula experimental, durante o mesmo período de monitoramento.

Assim como o Alumínio, o Manganês pode também apresentar propriedades tóxicas em condições de acidez, promovendo fitotoxicidade ao meio e interferindo na produtividade das culturas desenvolvidas. Segundo Pavan e Bingham [24] a toxidez do Manganês é um dos principais fatores que prejudicam o crescimento das plantas, ocorrendo comumente em conjunto com aquela causada pelo alumínio em condições ácidas. 
Em relação ao Cobre não se pode afirmar que houve interferência direta da presença desse elemento no crescimento e na germinação das sementes, uma vez que a quantidade de Cobre encontrada na concentração inicial (2,2 mg.kg-1) foi inferior a concentração considerada ótima para crescimento das plantas, que segundo Pais e Benton Jones [23] varia entre 3,0 e $10 \mathrm{mg} \cdot \mathrm{kg}^{-1}$. Em se tratando do Níquel, observa-se que a sua concentração no dado inicial de coleta pode ter contribuído também para fitotoxicidade dos resíduos nesse ponto, uma vez que esse elemento é solúvel em $\mathrm{pH}$ 5,5, contribuindo para aumentar seu efeito tóxico. Contudo, ao longo do tempo a toxicidade desse elemento diminui, devido a elevação do $\mathrm{pH}$ que permite que sua solubilidade seja diminuída.

Em relação ao Chumbo, não foi observado efeito fitotóxico desse elemento em relação ao crescimento e germinação das sementes de tomate e repolho. Embora o Chumbo seja facilmente absorvido e acumulado em diferentes partes das plantas, os teores encontrados nos resíduos foram bastante inferiores aqueles que causam fitotoxidez, que são de 100 a 400 mg. $\mathrm{kg}^{-1}$ (KABATA-PENDIAS \& PENDIAS [15]).

Além dos metais, o nitrogênio amoniacal presente na célula experimental também pode contribuir para fitotoxicidade. Os resultados obtidos para comportamento do nitrogênio amoniacal (Figura 3) corroboram com os dados de fitotoxicidade apresentados nas Figuras 4 e 5, nas quais se observam elevados índices de crescimento das raízes nos primeiros dias de monitoramento.

A toxicidade do nitrogênio amoniacal nas sementes de tomate e repolho se dá, principalmente, em função das variações do pH. Segundo Alabaster e Loyd [1] e Tomasso [30], o pH é a variável ambiental mais importante no controle da toxicidade do nitrogênio amoniacal. Em condições ácidas ou neutra existe uma predominância do íon amônio que não é tóxico e, em condições básicas a amônia livre prevalece no meio, causando toxicidade.

Embora as variações de $\mathrm{pH}$ não tenham influenciado diretamente no comportamento dos microrganismos presentes na célula experimental, devido a sua capacidade de retenção de agentes tóxicos na sua parede celular (MONTEIRO, [21]), contribuíram para promover a fitotoxicidade dos resíduos. Isso porque, diferentemente dos microrganismos que possuem defesas próprias com capacidade de se desenvolver em ambientes extremos, as plantas são sensíveis a alterações promovidas pelo meio. De acordo com Yamada [31] as plantas sofrem vários desarranjos devido a alterações na estrutura dos cloroplastos causadas pela toxicidade do nitrogênio amoniacal.

Na fase inicial de monitoramento, o nitrogênio amoniacal não exerceu efeito tóxico sobre o meio, não interferindo assim, nos processos de germinação e crescimento das sementes. Isso porque, nessa fase o $\mathrm{pH}$ da célula apresenta-se ácido com valores que tendem a neutralidade com o passar do tempo, fazendo com que prevaleça no meio a amônia na forma ionizada. Segundo Sawyer, et al. [26], a concentração total de nitrogênio amoniacal corresponde à soma das espécies $\mathrm{NH}_{3}$ e $\mathrm{NH}_{4}{ }^{+}$, sendo que, em $\mathrm{pH}$ neutro, mais de $99 \%$ da amônia apresenta-se na forma iônica (não-tóxica).

Contudo, após os 100 dias de monitoramento, embora a concentração de nitrogênio amoniacal na célula experimental tenda a decrescer, ocorre uma elevação do $\mathrm{pH}$, fazendo com que haja uma conversão da amônia não ionizada para a sua forma ionizada. Essa conversão promove o aumento da toxicidade no meio, e embora a concentração do nitrogênio amoniacal seja reduzido ao longo do tempo, seu efeito tóxico aumenta. Estudos realizados por Meade [18] mostram que a forma não iônica da amônia é 300-400 vezes mais tóxica do que a sua forma iônica.

\section{CONCLUSÕES}

A partir da análise do potencial tóxico dos resíduos sólidos urbanos da cidade de Campina Grande - PB pode-se concluir que:

- A toxicidade dos resíduos da cidade de Campina Grande - PB é mais elevada na fase inicial, quando seu $\mathrm{pH}$ apresenta caráter ácido.

- $\quad \mathrm{O}$ pH, os metais e o Nitrogênio Amoniacal são os principais responsáveis pela toxicidade dos resíduos, sendo o $\mathrm{pH}$ um fator limitante para que a toxicidade ocorra.

- O RSU presentes na célula experimental são tóxicos para o meio ambiente e a saúde pública, no entanto não são tóxicos para o processo biodegradativo. 
- Os testes de lixiviação realizados com as amostras de resíduos mostraram que os metais Alumínio, Manganês e Níquel encontram-se com teores elevados dentro da célula experimental de resíduos sólidos, com valores superiores aos LMP estabelecidos pela NBR 10.004/04.

\section{RECOMENDAÇÕES}

Em função da ineficácia de ações de gestão e gerenciamento dos resíduos sólidos urbanos na maioria dos municípios brasileiros, a partir deste estudo observou-se a necessidade do desenvolvimento de pesquisas voltadas a avaliação o potencial tóxico dos resíduos sólidos urbanos, principalmente em função dos impactos que estes podem causar. Assim, recomenda-se:

- Realização de estudos específicos para enquadramento dos RSU, visto que no Brasil normalmente esses resíduos são classificados como não inertes, contudo a introdução de compostos de diversas naturezas na composição destes resíduos pode alterar as suas características, tornando-os semelhantes aos resíduos industriais.

- Estabelecimento de padrões específicos para manuseio dos RSU por aqueles que trabalham diretamente com resíduos sólidos, seja nas instituições de ensino e pesquisa, seja nas atividades de coleta, triagem, transporte, transbordo e destinação final, em virtude do potencial tóxico que estes apresentam e dos impactos podem ocasionar a saúde pública e ao meio ambiente.

\section{BIBLIOGRAFIA}

[1] ALABASTER, J. S., LOYD, R., “Ammonia”, In: ALABASTER, J. S., Water quality criteria for freshwater fish, London: Bufterworth Scientific, pp. 361, 1982.

[2] ALCÂNTARA, P. B., Avaliação da influência da composição de resíduos sólidos urbanos no comportamento de aterros simulados, Tese de D. Sc., CTG/UFPE, Universidade Federal de Pernambuco, Recife, PE, Brasil, pp. 366, 2007.

[3] APHA - AWWA, Standard Methods for the Examination of Water and Wastewater, USA, 2012.

[4] ASSOCIAÇÃO BRASILEIRA DE NORMAS TÉCNICAS. NBR 10004: Resíduos Sólidos: Classificação, Rio de Janeiro, pp. 77, 2004.

[5] ASSOCIAÇÃO BRASILEIRA DE NORMAS TÉCNICAS. NBR 10005: Resíduos Sólidos - procedimento para obtenção de extrato lixiviado de resíduos sólidos, Rio de Janeiro, pp. 16, 2004.

[6] ASSOCIAÇÃO BRASILEIRA DE NORMAS TÉCNICAS. NBR 10006: Resíduos Sólidos - procedimento para obtenção de extrato solubilizado de resíduos sólidos, Rio de Janeiro, pp. 7, 2004.

[7] BRASIL, Ministério da Saúde. Portaria n 2.914, de 12 de Dezembro de 2011. Diário Oficial [da] República Federativa do Brasil, Poder Executivo, Brasília, DF, 13 de dezembro de 2001, Seção 1. pp. 266, 2011.

[8] CALLI, B., MERTOGLU, B., INANC, B. AND YENIGUN, O., "Effects of high free ammonia concentrations on the performances of anaerobic bioreactors", Process Biochemistry, v.40, n. 3-4, pp.1285-1292, 2005.

[9] CAMPOS, V. R., CAZARINI, E. W., "Estudo dos critérios de decisão para localização de aterros sanitários para auxiliar na avaliação de impactos ambientais”. In: $3^{\circ}$ Simposio Iberoamericano de Ingeniería de Residuos e $2^{\circ}$ Seminário da Região Nordeste sobre Resíduos Sólidos, João Pessoa, Setembro, 2010.

[10] CHANG, A.C., GRANTO, T.C., PAGE, A.L., "A methodology for establishing phytotoxicity criteria for chromium, copper, nickel and zinc in agricultural land application of municipal sewage sludges”, Environmental Quality, v.21, pp. 521-536, 1992.

[11] CINTRA, I. S., Estudo da influência da recirculação de chorume cru e chorume inoculado na digestão anaeróbia de resíduos sólidos urbano,Tese de D.Sc., Universidade Federal de Minas Gerais, Belo Horizonte, MG, Brasil. pp. 457, 2003.

[12] EDUARDO, J. Avaliação das características microbiológicas e físicoquímicas do lixiviado (chorume) no processo de tratamento do Aterro Metropolitano de Gramacho, Dissertação de MsC., Universidade do Estado Rio de Janeiro, Rio de Janeiro, RJ, Brasil, pp.98, 2007. 
[13] Garcez, L. R., Estudo dos componentes tóxicos em um biorreator de resíduos sólidos urbanos da cidade de campina grande - PB, Dissertação de M.Sc., CTRN/UFCG, Universidade Federal de Campina Grande. Campina Grande, PB, Brasil, pp. 114, 2009.

[14] JAHNEL, M. C., MELLONI, C., ELKE, J. B. N., "Maturidade de composto de lixo urbano”, Scientia Agricola, v.56, pp.301-304, 1999.

[15] KABATA-PENDIAS, A., PENDIAS, H., Trace elements in soils and plants, CRC Press, Inc. Boca Raton, pp. 315, 1985.

[16] KABATA-PENDIAS, A., PENDIAS, H., Trace elements in soil and plants, 2.ed., Florida, CRC Press, pp. 365, 1992.

[17] KIEHL, E. J., Manual de compostagem: Maturação e qualidade do composto, São Paulo, Piracicaba, pp. $171,1998$.

[18] MEADE, W. J., “Allowable ammonia for fish culture”, Progressive fish culturist, v.47, n.3, pp.137-142, 1985.

[19] MELO, M. C. Uma análise de recalques associada à biodegradação no aterro de resíduos sólidos da Muribeca. Dissertação de M.Sc. CTG/UFPE, Universidade Federal de Pernambuco. Recife, PE, Brasil, pp. 141, 2003.

[20] MESQUITA FILHO, M. V., SOUZA, A. F., "Resposta do tomateiro à aplicação da calagem e da adubação fosfatada”. In: Congresso brasileiro de olericultura, Salvador, Resumos, Hortic. Bras., pp. 61-66, 1986.

[21] MONTEIRO, V. E. D. Análises físicas, químicas e biológicas no estudo do comportamento de aterro da muribeca, Tese de D.Sc, CTG/UFPE, Universidade Federal de Pernambuco, Recife, PE, Brasil, pp. 246p, 2003.

[22] MONTEIRO, V. E. D. M., MELO, M. C., ALCÂNTARA, P. B., et al., "Estudo do comportamento de RSU em uma célula experimental e suas correlações com aspectos microbiológicos, físicos e químicos”, Artigo técnico, Engenharia Sanitária e Ambiental, v.11, n.3., 2006.

[23] PAIS, I., BENTON JONES, J., The handboook of trace elements, Florida, St Lucie Press, pp. 223, 1997.

[24] PAVAN, M. A., BINGHAM, F. T., “Toxidez de metais em plantas”, In. Caracterização de toxidez de manganês em cafeeiros, Pesquisa Agropecuária Brasileira, Brasília, v.16, n.6, pp.825-821, 1981.

[25] RIBEIRO, L. S., Estudo da degradação dos resíduos sólidos urbanos através dos parâmetros físicos e físico- químicos em um biorreator de escala, Dissertação de M.Sc. CTRN/UFCG, Universidade Federal de Campina Grande, Campina Grande, PB, Brasil, pp. 136, 2012.

[26] SAWYER, C. N., MCCARTY, P. L., PARKIN, G. F., Chemistry for environmental engineering., 4 ed., New York, McGraw-Hill Inc., pp.168-174, 1994.

[27] SILVA, A. S., Avaliação da toxicidade dos Resíduos Sólidos Urbanos da cidade de Campina Grande, Dissertação de M.Sc. CTRN/UFCG, Universidade Federal de Campina Grande, Campina Grande, PB, Brasil, pp. 139, 2012.

[28] TCHOBANOGLOUS, G., THEISEN, H., VIGIL, S., Integrated Solid Waste Management Engineering Principles and Management Issues, McGrall-Hill, Inc., New York, pp. 949, 1993.

[29] TÍQUIA, S. M., HODGKISS, I. J., Effects of Composting on Phytotoxicity of Spent Pig-manure Sawdust Litter, Hong Kong, pp. 249-256, 1996.

[30] TOMASSO, J. R., "Toxicity of nitrogenous wastes to aquaculture animals", Reviews in Fisheries Science, Amsterdam, v. 2, n.1, pp. 291-314, 1994.

[31] YAMADA, T., Melhoria na eficiência da adubação aproveitando as interações entre os nutrientes. Informações agronômicas n. 100. Dezembro de 2002. Disponível em:

http://apostilas.cena.usp.br/Lavres/ContatoIonRaizeAbsorcaodenutrientes.pdf. Acesso em: Outubro de 2012. 